\title{
IDEF0-Technology of Modeling of Processes of Minimization the Resistance of the Personnel to Organizational Changes at the Enterprise
}

\author{
STASHKEVYCH IHOR \\ Department of Computer Information Technologies \\ Donbass State Engineering Academy \\ 39, Mashinobudivnykiv blvd., Kramatorsk’s, 84313 \\ UKRAINE \\ TURLAKOVA SVITLANA \\ Department of Financial and Economic Problems of Production Potential Employment \\ Institute of Industrial Economics of the National Academy of Sciences of Ukraine \\ 2, Marii Kapnist Str., Kyiv, 03057 \\ UKRAINE \\ SHEVCHENKO OLENA \\ Department of Management \\ Donbass State Engineering Academy \\ 39, Mashinobudivnykiv blvd., Kramators`k, 84313 \\ UKRAINE \\ DERZHEVETSKA MARYNA \\ Department of Medical Physics and Information Technology \\ Donetsk National Medical University \\ 39, Mashinobudivnykiv blvd., Kramators`k, 84313 \\ UKRAINE
}

\begin{abstract}
The structural and functional IDEF0-model of information support of processes of minimization of resistance of the personnel to organizational changes at the enterprise is developed. The proposed model makes it possible to describe in a logical, convenient and consistent form the relationship between management functions and responsible executives, provides information about resources, information flows, instructions, regulatory information, a set of models and approaches. The corresponding model in the notation IDEF0 will provide information support for decision-making on the management of organizational changes at the enterprise.
\end{abstract}

Key-Words: - information interaction, personnel, decision support, information modeling, structural and functional model, IDEF0-model, enterprise.

Received: December 28, 2019. Revised: April 28, 2020. Accepted: May 5, 2020. Published: May 12, 2020.

\section{Introduction}

Studies of general economic indicators of development of Ukraine, its industry and individual sectors in 2014-2018 [1] show a positive change in the negative dynamics of development, but to fully overcome the consequences of the domestic systemic economic crisis is still far, which increases the importance of timely and targeted changes. The search for new ideas and technologies is impossible without changes in the enterprise. The peculiarity of their implementation is associated with the presence of the human factor and the importance of its consideration in the formation of plans for organizational changes.

Resistance to organizational changes may be due to insufficient awareness of the staff about the nature of the changes and the nature of the team members, as well as the objective disadvantage of changes for the staff (additional load, increased responsibility, 
the need for additional training, etc.). Manifestations of resistance may be either passive (reduction of labor productivity, negligence, etc) or active (campaigning against the changes, the formation of a resistance group, refusing to carry new responsibilities, etc.). Forecasting of collective reactions to changes is complicated by the fact that in the teams of employees of enterprises there is an intensive information interaction, as a result of which the final level of decision support can change. This is the reason for the relevance of the study of the processes of minimizing staff resistance to organizational changes in enterprises to make informed management decisions on the implementation of changes in business practices. The efficiency of the enterprise is largely due to the presence of a single information management system. That is why an important prerequisite for the development of the enterprise is the availability of appropriate information support processes to minimize the resistance of personnel to organizational changes.

\section{Problem Formulation}

A lot of works of scientists, namely: I. Ansoff [2], W. Barnet [3], M. Voronovitsky [4], A. Goodson [5], D. Kotter [6], R. Lepa [7, 8], S. Turlakova [9], K. Sewchurran [10], A. Pushkar [11], N. H. Heorhiadi [12], O. Bezchasnyi [13] etc. are devoted to conceptual and practical bases of research of processes of minimization of resistance of the personnel to traditional changes at the enterprises, and also to problems of information modeling of these processes. Despite the fact that scientists have studied the peculiarities of interaction between team members and their impact on enterprises, the approaches existing in science today do not allow formalizing the processes of assessing the level of decision support at enterprises by team members and taking into account information interactions between them at the level of an information model. In the paper [8] the authors consider in detail the mechanism of minimization the resistance of personnel to organizational changes at the enterprise, but the question of information support for the implementation of the development remains open.

Therefore, issues related to information modeling of processes of minimization the resistance of the personnel to organizational changes at the enterprise, require further research and the consideration for timely implementation of the assessment of the level of support changes and decision making at enterprises. In this regard, the purpose of the article is formalization at the level of information model processes to minimize the resistance of personnel for organizational changes at the enterprise to make informed management decisions on the implementation of changes in the practice of enterprises.

The initial statement of the problem is that there is a certain collective in which it is planned to implement decision on the implementation of any organizational innovation that affects this collective, while it can affect to varying degrees the individual members of the collective and have different benefits for them. It may require additional time for the employee to adapt to the innovation or otherwise worsen his / her situation (it is possible to reduce authority, income and available resources, retraining, etc.) - these factors contribute to the reduction of the employee's support for the decision. Or the decision can be profitable - it can provide the employee with additional powers, facilitate work, provide the employee with additional free time, increase his income, promote moral satisfaction from work, etc. The input parameters of the model are the following data: initial level of support for organizational change by individual team members; objective profitability of organizational changes for them; the authority of team members in the eyes of each other; list of potential activities aimed at increasing the level of support for organizational changes; parameters of cost and effect functions (impact of potential measures on the initial level of support for organizational changes and their objective profitability for individual team members); budgetary constraints on the implementation of activities; targets (target average support level, support level structure, thresholds, formation of groups with high support, prevention of formation of groups with low support, etc.). The output of the model are the following data: the final level of support for organizational changes by individual team members (after information exchange); the list of selected activities, as well as their intensity for each of the team members; degree of achievement of the set targets; expenditure and percentage of use of the allocated budget. At the same time, the task of minimization of organizational resistance can be solved by purposefully reaching a certain initial level of support for the solution among the most authoritative members of the team, who then, in the course of interaction with other members of the team, transfer their opinion to other members of the team. 


\section{$3 \quad$ Problem Solution}

Among the main goals and criteria which express the task of minimizing organizational resistance are: formation in the team of a certain specified average level of support for theimplementation of the solution under consideration (not lower than a certain target value) in order to create a general climate in the team that is favorable to changes; minimization of the number of team members who are openly opposed to organizational change. This statement of the problem in practice allows to minimize extreme cases of organizational resistance in the team, to prevent the formation of groups of employees who jointly implements their organizational resistance. The conceptual provisions of minimization the resistance of the staff to organizational changes at the enterprises, in the framework of which is developed the approach to the assessment of the level of support organization changes in the team after the information interaction between the staff members and the approach to decision making in the branch of management of minimization the resistance of the staff to organizational changes at the enterprise, based on optimzation model of decisions selection are proposed in the paper [8]. But the implementation of the approaches [8] presented in the work to minimize the resistance of personnel to organizational changes in the industrial enterprise requires processing and systematization of multidirectional information flows, and a significant number of participants should be involved. In this regard, it becomes relevant to build an information model of the problem being solved.

\subsection{Building an information model}

\subsubsection{Overview of existing methods}

Different approaches are used for data analysis in information systems, such as: structural and functional analysis, object-oriented and mixed analysis [14]. Structural analysis primarily uses tools that illustrate the functions performed by the system and the relationships between data. Each group of funds corresponds to certain types of models (diagrams).

Among the formal modeling tools used for the structural analysis of complex control systems, methodologies are widely used SADT (Structured Analysis and Design Techniques), DFD (Data Flow Diagram), ERD (Entity Relationship Diagram), STD (State Transition Diagrams) и др.
SADT (Structured Analysis and Design Techniques) standards implement a structural approach to system modeling [14]. SADT-technology is focused on a comprehensive presentation of the structure of the system, including information flows and communication links. At the same time, the system under consideration retains a holistic view in which all the constituent components are interconnected. Diagrams of data flows DFD (Data Flow Diagram) depict data transfer between operations and characteristics of the information side of the business processes of the described system. It also shows how the information undergoes changes and where it is stored. The company's activities are decomposed into logical information levels, and the basic scheme is improved by adding detailed descriptions of subprocesses, which also have their own internal structure [14].

ERD (Entity-Relationship Diagrams) models of the "entity-relationship" type allow to describe conceptual schemes of the domain and are used in the conceptual design of databases [15].

STD (State Transition Diagrams) state transition diagrams are designed to model and document those aspects of business processes that depend on time or reaction to an event. The simulated process at any given point in time is in exactly one state from their finite set. Over time, it can change its state, while STD accurately determines the transitions between states [15].

\subsubsection{Application of a structural approach to modeling the problem being solved}

Structural and functional analysis is the most effective in providing opportunities for detailed analysis and systematization of information flows. Its application will be the most effective and convenient for the implementation of the monitoring system of organizational resistance in the team of the enterprise. The most spread has received the notation IDEF0 (Integration Definition for Function Modeling). Its main advantages include convenience and the ability to visualize the information, as well as availability to users. IDEF0 has the ability for simultaneously display resources, mechanisms, management activities and execution process results. IDEF0 is a notation for creating of process model that shows the structure and processes of the system, as well as the flows of information and material objects that link these processes [14-16]. Thus, the IDEF0 functional modeling methodology essentially involves the identification of business processes, their decomposition to the required degree of detail, and also, using clear notation for 
the inputs and outputs of each function, linking all functions into a single model according to the information and communication relationships of the main functions in a real system. The advantage of the models constructed in this way is that they are easy to discuss with domain experts due to their visual graphic presentation, and, in addition, the basic system concepts form the domain dictionary, which is laid down in the future information system for the system.

The main drawback of the structural approach is that processes and data exist separately from each other, and design is carried out from processes to data. Thus, in addition to functional decomposition, there is also a data structure that is in the background. However, to study the problem under consideration, the need to divide the technology of work into separate fragments will allow us to present a detailed data structure and determine the main information interactions [17].

Thus, the formation of diagrams IDEF0 is the most effective for the development of information ensuring the processes of minimization the resistance of personnel to organizational changes at the enterprise. In figure 1 (Appendix 1) the context diagram of information model of processes of minimization of resistance of the personnel to organizational changes at the enterprise is presented (A0).

Block 1, Fig.1 reveals the process of assessing the level of support for organizational changes by team members. The tools for assessing organizational resistance, as well as a model for assessing the level of support for organizational changes after the implementation of information interaction between team members are presented as mechanisms for the implementation of processes. The implementation of this process is provided by the staff of the center for monitoring organizational resistance in the personnel service. Taking into account the specifics of the incoming information, which should be collected and summarized to assess the tendency to conformism of the members of the collective and to assess the level of support for changes by the members of the collective after interaction, the monitoring center should include qualified psychologists, as well as specialists in personnel assessment and certification. Regulation of the implementation of this process is disclosed in the framework of scientific and methodological approach to assessing the support of organizational changes by team members. The decision making process in the field of management of the level of support for organizational changes in the team is presented in block 2, Fig.1. The mechanisms of implementation of the process are defined: the apparatus of economic and mathematical modeling, the model of choice of measures to increase the level of organizational support for changes. The implementation of the process is entrusted to the management of the personnel service, and the regulation of the process is disclosed in the framework of scientific and methodological approach to decision making in the field of management of the level of support of organizational changes in the team. Based on the results of this process, we obtain a solution in the field of management of the level of support for organizational changes in the team. This information, as well as should be obtained in block 1, Fig. 1 information about the tendency of team members to conformism and the level of support for changes by team members should be used in the process of monitoring the level of support for organizational changes in the team (block 3, Fig.1). Regulation of the monitoring process is presented in the framework of the approach to monitor the level of support for organizational changes in the team. The mechanism of the implementation process is vested in the monitoring centre of organizational resistance in the personnel office and units of the enterprise in which changes are made. Based on the results of this process, we obtain measures for increase the level of support of organizational changes, as well as the option of solution adjusting if necessary. Decomposition of block 1 is presented in the form of information support of the process of assessment of the level of support of organizational changes by the team members (Fig.2, Appendix 2), where the following subprocesses are identified: determining the propensity of a team member to conformism (block 1.1), assessment the level of support by a team member for a solution (information interaction) (1.2), determining the change in the opinions of team members as a result of the act of information interaction (1.3). The input information to block 1.1 is: the level of competence of the team members, the level of complexity of the problem, the type of personality of the team members, information on consistency, the presence of allies, the possibility of a public response, the level of awareness of the team on the problem and the complexity of the problem. The input information of the 1.2 block is: the objective profit ability of changes for each member of the team, as well as the initial opinion about the changes of each team member. At the entrance to block 1.3, information is provided about the authority of the team members in the eyes of each other, as well as about the size and composition of the group. 


\subsection{Implementation of the proposed model at the enterprise}

Druzhkovka machine-building plant (DMP) [18], which is the largest producer of mining equipment in the CIS, has been chosen as the object of implementation, and in such types as mechanized supports, mine and mining trolleys, it is a monopolist in Eastern Europe. One of the reasons of crisis phenomena which are now observed at the enterprise is lack of timely improvement of organizational structure and introduction of the approaches to management corresponding to the current social and economic situation and a condition of the market. This is caused by insufficient operational actions of the management and a significant potential of organizational resistance in the team. The current situation makes difficult to implement organizational changes in two direct ways: the lack of attractive wages reduces the motivation of staff and increases dissatisfaction in the case of the imposition of new functions on the employee, the need for training ets.; due to the reduction of competition for jobs in the industry and in this locality (for low wages, shortage of specialists and the pre-retirement age of qualified specialists), employees receive additional levers of pressure on the management, forcing it not to carry out significant organizational changes that can cause discontent in the team. One of the tasks associated with organizational changes at DMP is to improve the work of the cutting area. Inefficiency of organizational interaction led to failures in providing other shops with blanks, losses due to suboptimal cutting of metal, an increased percentage of waste, suboptimal use of waste, there was a lack of control over the work of the site. Total losses due to these reasons are more than 2 million UAH per year. To solve the identified problems, a new organizational model of interaction between the personnel of the cutting site is proposed, which involves the introduction of a system of transfer of material responsibility between the personnel of this site. As a result, additional responsibilities are placed on staff: a picker must keep a journal of the actual receipt of blanks from the emploees; each employee is obliged to check that a picker has specified in the magazine the number of the transferred preparations and has put the signature that confirms their acceptance; an accountant clerk needs to check that the data on number of produced workpieces in a closed shift-day job (SDJ) match the actual number of workpieces transferred in the pantry; a storekeeper on the basis of the actual metal residues after cutting should update information on business waste in the sheet of metal residues, transfer it to the head of the planning and calculation bureau, production planning engineer and technologist of the metal structures shop; a technologist on the basis of a statement of residual metal and detailed business waste, SDJ should form the sheet metal and pass it to the master, to carry out the distribution of the metal at the cutting in the sheet metal. This information should be available a production planning engineer and a storekeeper, on the basis of which he issues the metal and should monitor and analyze the cost of metal after cutting. Thanks to the proposed organizational changes, the company expects to receive an economic effect in the amount of $1500000 \mathrm{UAH}$ per year by reducing losses from 2 million to $500000 \mathrm{UAH}$ per year as a result of saving metal due to its more rational use, preventing cases of unjustified write-off of metal and removal of business waste by workers under the guise of scrap metal, general improvement of labor discipline and responsibility. The study showed that the proposed scheme of organizational changes can cause discontent among the staff of the cutting site. In particular, staff: negatively attitude to the inclusion of his duties of new features that require more intensive workload for the same duration of the shift; sceptically about the emergence of new control instruments, the absence of which had previously allowed to escape personal responsibility for inadvertent damage to the workpiece, errors, metal cutting, the disappearance of residues due to negligence or theft; sceptically about the introduction of cutting optimization -the workers used to work "how convenient" and have no enthusiasm for the guidance of optimal cutting, so, in their opinion, this casts doubt on their professional quality; afraid of sanctions for failure to comply with new regulations. Therefore, before implementing organizational changes, it is necessary to take measures to increase the level of their support in the team. On the basis of interviewing the personnel of the cutting area, as well as the analysis of data from the staff and the management of the metal structures workshop, the assessment of the characteristics of employees and an objective assessment of the profitability of organizational change was carried out (table 1). 
Table 1. The characteristics and authority of employees in the eyes of other

\begin{tabular}{|c|c|c|c|c|c|c|c|c|c|c|c|c|c|}
\hline es & 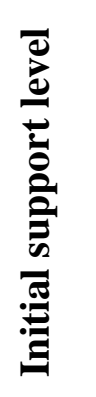 & 总总 & 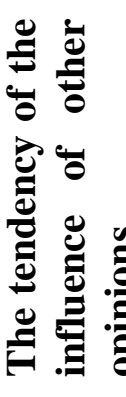 & 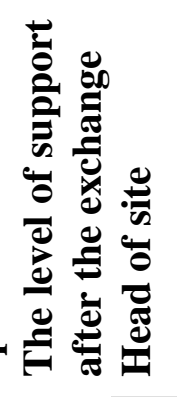 & 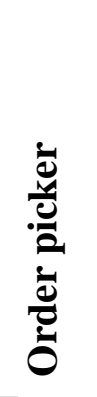 & 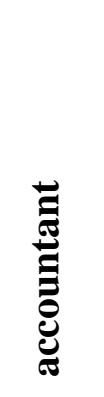 & 㐫 & 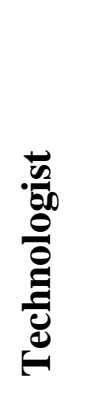 & 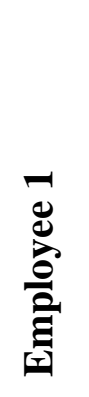 & 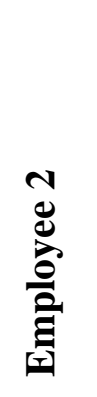 & 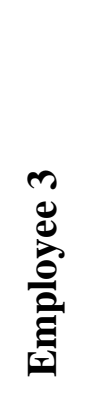 & 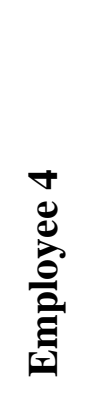 & م0 \\
\hline 16 & 0,1 & 0,25 & 015 & $0,121,00$ & 0,80 & 0,75 & 0,78 & 0,94 & 0,95 & 0,73 & 0,87 & 0.93 & n \\
\hline Ord & 0,37 & 0 & & 6 & 0 & & & 0 & & & & & 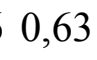 \\
\hline Acc & 0,53 & 0 & & 47 & 8 & 00 & 0 & 0,49 & & & & & 5 \\
\hline Sto & 0 & & & & & & & & & & & & \\
\hline ec & 0,8 & & & & & & & 1,00 & & & & 0 & 0,44 \\
\hline Eml & 0,13 & & & & & & & & 1 , & 0 , & & & 0 \\
\hline Em & 0,32 & 0 & & & & 0 & 0 & 0 & 45 & 1,00 & 0,41 & 0,40 & 0,51 \\
\hline & 0,11 & & & & & & 0 , & & & & 1,00 & 0,51 & 0,56 \\
\hline & 0,15 & 0,1 & & & 47 & 0,51 & 0,60 & 0,56 & 0,54 & 0,52 & 0,49 & 1,00 & 0,37 \\
\hline & 0,69 & & & 0,570 & & 0,49 & 0,50 & 0,45 & 0,37 & 0,38 & 0,51 & 0,49 & 1,00 \\
\hline Mean value & 0,39 & 0,195 & 0,58 & 0,37 & & & & & & & & & \\
\hline
\end{tabular}

On the basis of the received estimates it is conclusions: objective profitability of changes for employees is low; despite the low objective profitability of changes for the technologist, he demonstrates a high level of support, so he believes that the changes are painful, but correct; after the information exchange between the team members, the level of support is reduced from 0.39 to 0.37 , and this is largely facilitated by the position of the head of the site. Grouping by support levels is as follows: active support of organizational changes $(0$ employees $-0 \%$ of the team); support of organizational changes $(2-20 \%)$; neutral position $(2-20 \%)$; hidden resistance to organizational change $(2-20 \%)$; active resistance to change (4$40 \%$ ). The general conclusion is that at the formed level of support organizational changes can not be carried out, as this can lead to active organizational resistance and even the formation of group forms of resistance to organizational changes.

Even if we manage to suppress the resistance of the administrative measures, the effectiveness of the changes that will undermine latent forms of organizational resistance and sabotage. There are two ways to solve the problem of increasing the level of decision support in the team: the impact on the objective profitability of decisions (by improving working conditions, increasing wages, the use of incentive measures of an intangible nature or adjusting organizational changes) and the impact on the initial level of decision support by individual members of the team. In preparation for the implementation of organizational changes developed the list of activities to improve the initial level of support and the objective profitability of solutions for team members: salary increase by $10 \%$ (sales c osts $50000 \mathrm{UAH}$ ); salary increase by $20 \%$ (100 $000 \mathrm{UAH})$; prize in the amount of $10 \%$ for the implementation of standards (32000 UAH); prize in the amount of $20 \%$ for the implementation of standards (64 $000 \mathrm{UAH})$; trainings (20 $000 \mathrm{UAH})$; reorganization of logistics department under the new requirements (50000 UAH). With the use of the proposed information model, the measures for implementation are chosen, which will allow to solve the following tasks at the minimum total cost: reducing the percentage of employees demonstrating active resistance to $0 \%$; increase the percentage of employees demonstrating active support to at least $30 \%$; achieve the target average level of support to not less than 0.5. Such parameters will allow to realize the project of organizational changes without significant delays, sabotage and undermining the atmosphere in the team. To solve the tasks in the optimization model, the corresponding function minimization of costs and corresponding to task constraints were used. The calculations were made using the model [8] allowed to choose the optimal set of measures that meet the above criteria and achieve the necessary 
profile of support for organizational changes in the team (table 2): a salary increase of $10 \%$, training and reorganization of the logistics department under the new requirements. The total cost is $120000 \mathrm{UAH}$. Due to the implementation of changes, the average overall level of support after the information exchange shows an increase from 0.37 to 0.57 . The calculations, to be performed with the use of the information model, may be made it possible to choose an optimal set of measures, through which the necessary of support for organizational changes is achieved. The economic effect, calculated as a risk between the amount of losses from organizational resistance, which was prevented in the implementation of organizational changes without prior implementation of measures to reduce organizational resistance $(750000)$ and costs for the implementation of measures to increase the level of support for organizational changes (120 $000 \mathrm{UAH})$, amounted to $630000 \mathrm{UAH}$.

Table 2. Characteristics of employees after the implementation of measures

\section{Employees}

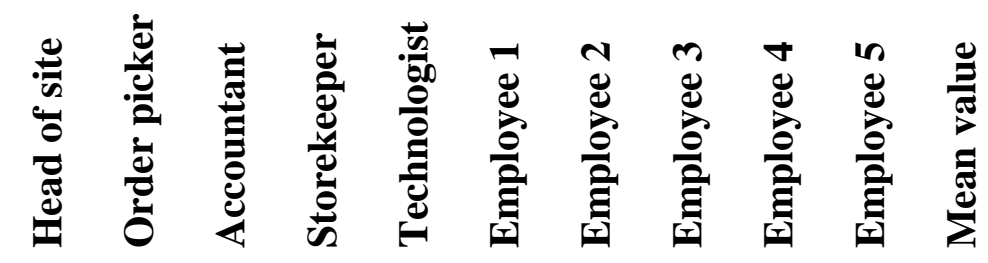

\begin{tabular}{clllllllllll} 
Initial support level & 0,47 & 0,6 & 0,84 & 1,24 & 0,97 & 0,57 & 0,77 & 0,51 & 0,61 & 1,04 & 0,762 \\
Objective profitability & 0,45 & 0,42 & 0,55 & 0,5 & 0,2 & 0,35 & 0,35 & 0,35 & 0,35 & 0,35 & 0,37 \\
Level of support (after) & 0,44 & 0,53 & 0,63 & 0,93 & 0,89 & 0,32 & 0,49 & 0,26 & 0,39 & 0,79 & 0,57 \\
\hline
\end{tabular}

\section{Conclusion}

Thus, the developed structural and functional model of information support processes to minimize the resistance of personnel to organizational changes at the enterprise develops the scientific and methodological approach to assessment of support level at the enterprise team decisions related to organizational changes. The use of IDEF0 notation for modeling the processes of minimization the personnel resistance to organizational changes at the enterprise provides advantages in relation to visual and convenient for understanding representation of the structure of processes, input and output flows, mechanisms and control actions, which will contribute to the efficiency and effectivity of the practical implementation of approach. And it makes the possibility to carry out the functional decomposition of the processes of minimizing the resistance of personnel to organizational changes in the enterprise and presenting them in the form of the set of hierarchically ordered, interrelated diagrams.

The formalization within the information model of the influence of information interaction between team members on the final level of decision support at enterprises, taking into account the characteristics of individual team members (the initial level of decision support, the authority of other team members, the tendency to adopt someone opinion), as well as the mutual influence of team members on each other in the implementation of information interaction, allows to visualize the evaluation process and to analyze the influence of various input factors on the final level of decision support in the team. A distinctive feature of the proposed approach is the possibility of its adaptation to the specifics of a particular enterprise within the framework of the existing organizational of it structure. The main purpose of the model is to provide information support for decision making to minimize the resistance of a person to organizational changes at the enterprise. Approbation of the results of the study, carried out at the DMP, has confirmed the effectiveness of the results. Thus, at the cutting site, the need for measures to increase the level of support by the team for organizational changes aimed at implementing approaches to the rational use of metal and business waste, as well as to strengthen the control of the transfer of responsibility between employees was justified. The calculations performed using the developed information model allowed to choose the optimal set of measures, thanks to which the necessary profile of support of organizational changes in the team is achieved. The economic effect, calculated as the difference between the amount of losses from organizational resistance, which was prevented in the implementation of changes without prior implementation of measures to reduce organizational resistance and the cost of implementing measures to increase the level of 
support for organizational changes amounted to $630000 \mathrm{UAH}$. In general, the concept of modeling the processes of minimizing the resistance of staff to organizational change in enterprises, which differs from existing integrated models of assessing the level of support for organizational change by team members, taking into account information interactions between them and models of proactive implementation of measures to increase support. decisions in the field of minimizing the manifestations of organizational resistance

A promising area of research is the problem of implementing information models of processes to minimize the resistance of personnel to organizational changes in the practice of industrial enterprises in order to minimize organizational resistance and achieve the target level of decision support at enterprises.

References:

[1] State Statistic Service of Ukraine. Access mode: http://www.ukrstat.gov.ua.

[2] Ansoff I., Macdonnel J., Implanting Strategic Management, New York: Prentice Hall, 1990.

[3] Barnett W.P., Carroll G.R., Modeling Internal Organizational Change, Annual Review of Sociology, 21, 1995, pp. 217-236, doi: 10.1146/annurev.so.21.080195.001245

[4] Voronovitsky M.M., Model of Herd Behavior of Bank Clients, Economics and mathematical methods, Vol. 49, №1, 2013, pp. 73-87 [in Russian].

[5] Judson A.S., Changing behavior in organizations: Minimizing resistance to change, USA Mass; Cambridge: Basil Blackwell, 1991.

[6] Kotter J.P., Leading Change: Why Transformation Efforts Fail. Harvard Business Review, Vol. 85, №1, 2007, pp. 96-103, doi: 10.1109/EMR.2009.5235501.

[7] Lepa R.N., Upravlenie razvitiem promyshlennyh predpriyatij $v$ usloviyah neoindustrializacii: mehanizm, modeli $i$ metody, In A. Ohten, \& R. Prokopenko (Eds.)., Kiev: NAN Ukrainy, In-t ekonomiki prom-sti, 2016 [in Russian], uri: http://iep.donetsk.ua/publish/mono/Lepa_Okhte n prokopenko2016.pdf.

[8] Lepa R.M., Okhten O.O., Stashkevich I.I., Minimizing personnel resistance to organizational changes at enterprise, Econ. promisl., Vol. 75, №3, 2016, pp. 90-115 [in Ukrainian],

doi:

10.15407/econindustry2016.03.090

[9] Turlakova S.S., Instrumenty refleksivnogo upravleniya stadnym povedeniem agentov na predpriyatiyah, Upravlinnya ekonomikoyu: teoriya ta praktika., 2017, pp. 133-149 [in Russian], uri: http://dspace.nbuv.gov.ua/handle/ $123456789 / 141376$

[10] Sewchurran K., Toward an approach to create self-organizing and reflexive information systems project practitioners, International Journal of Managing Projects in Business, Vol. 1, №3, 2008, pp. 316-333, doi: 10.1108/17538370810883792.

[11] Pushkar A.I., Potrashkova L.V., Modelirovanie upravleniya razvitiem predpriyatiy na osnove soglasovaniya interesov ekonomicheskih sub'ektov, Ekonomicheskaya kibernetika, 1-2 (19-20), 2003, pp. 22-33 [in Russian].

[12] Heorhiadi N.H., Shpak N.O., Vankovych L.Y. Reflexive management of the diffusion of enterprise innovational activity results, Scientific Bulletin of Polissia, 2017, Vol. 10, №2, Part 2, 2017, pp. 8-15.

[13] Bezchasnyi O., Reflexive coordination of communications in the construction of models for the development of an industrial enterprise, Virtual Economics, 1, №1, 2018, pp. 66-83, doi: 10.34021/ve.2018.01.01(5).

[14] Vallespir B., Ducq Y., Enterprise modelling: from early languages to models transformation, International Journal of Production Research, Vol. 20, №43, 2018, pp. 2878-2896, doi: 10.1080/00207543.2017.1418985

[15] Babenko, V., Nakisko, O., Latynin, M., Rudenko, S., Lomovskykh, L., and Girzheva, O. (2019). Procedure of Identifying of the Parameters of the Model of Management of Technological Innovations in Economic Systems, 2019 IEEE International ScientificPractical Conference Problems of Infocommunications, Science and Technology (PIC S\&T), Kyiv, Ukraine, 324-328. doi: 10.1109/PICST47496.2019.9061259

[16] Perevozova, I., Daliak, N., Babenko, V. (2019). Modeling of Financial Support for the Competitiveness of Employees in the Mining Industry. CEUR Workshop Proceedings, vol. 2422, pp. 444-454.

[17] Turlakova S.S., Information and communication technologies for the development of "smart" industries, Econ. promisl., Vol. 85, №1, 2019, pp. 101-122 [in Russian], doi: http://doi.org/10.15407/ econindustry 2019.01.101

[18] Publichne aktsionerne tovaristvo «Druzhkivskiy mashinobudivniy zavod». http://www.smida.gov.ua/db/participant/00165 669 
Appendix 1

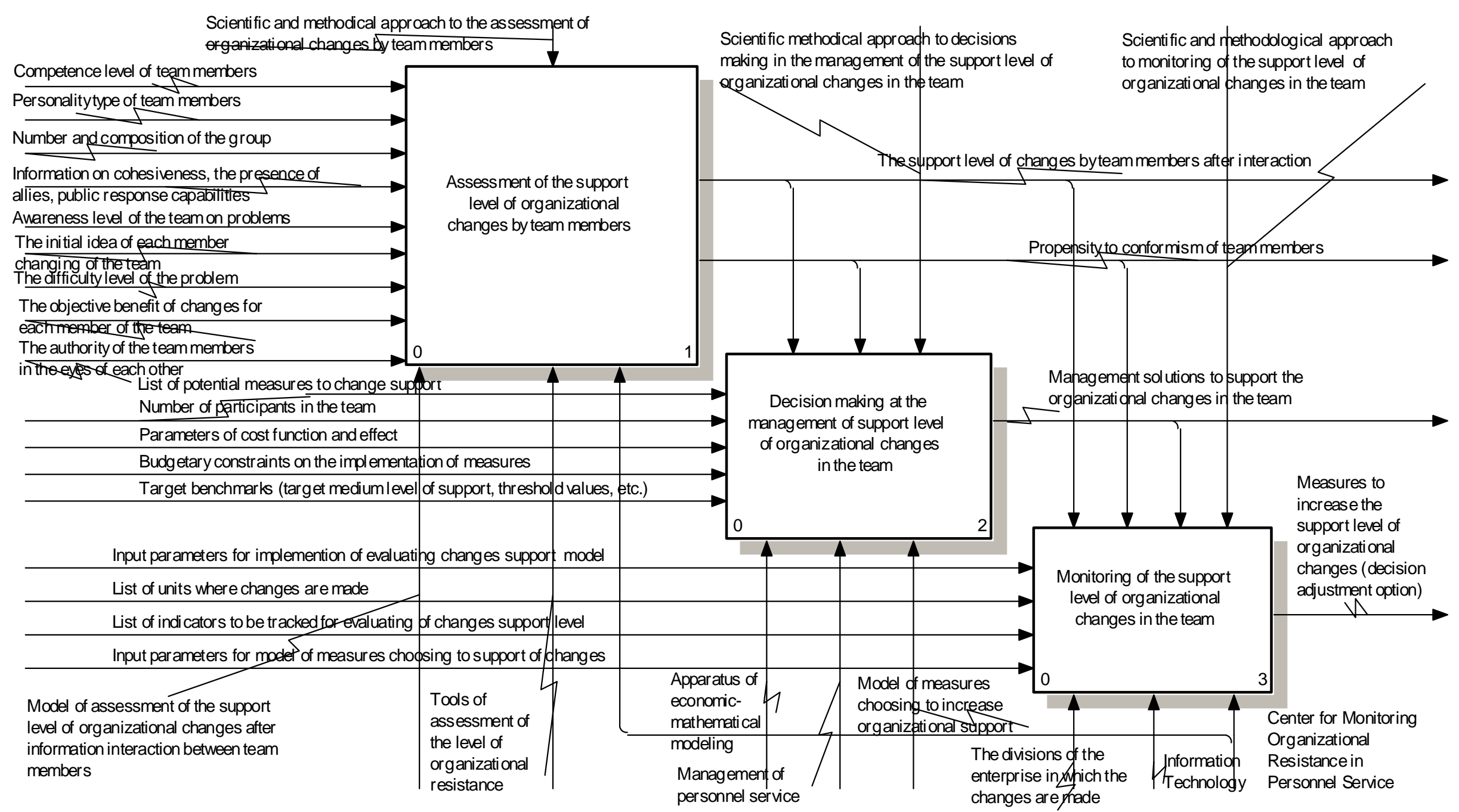

Fig.1. Context diagram of information model of personnel resistance minimization processes to organizational changes in the enterprise (the first level of decomposition) 


\section{Appendix 2}

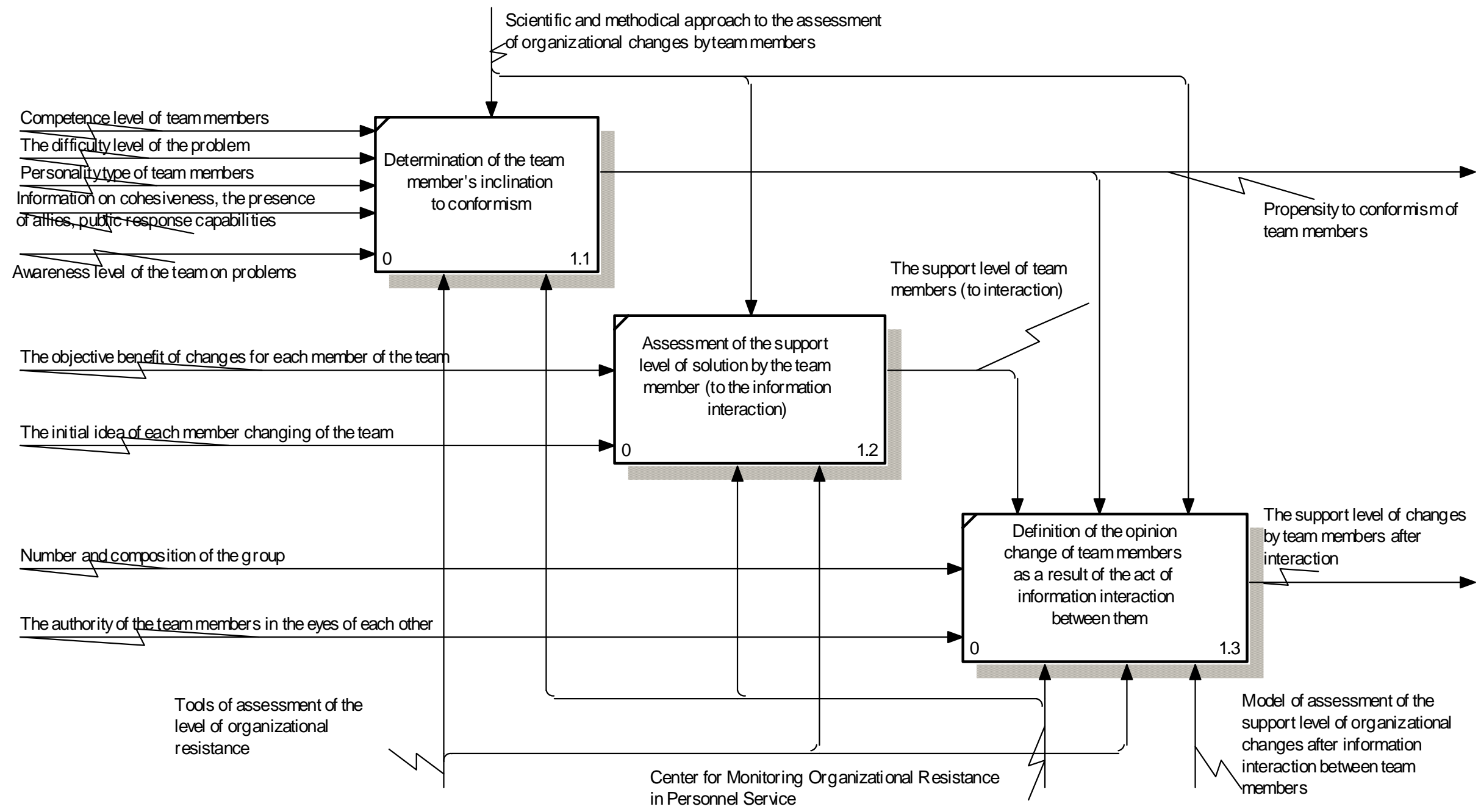

Fig.2. Diagram of detailization of the process of assessment the support level for organizational change by team members (second level) 


\section{ACKNOWLEDGEMENT}

We would like to thank all the reviewers for their thoughtful comments and efforts towards improving our manuscript. We revised the manuscript with special attention to the comments that we received from 3 reviewers that they were experts, specialist in the area of our paper. 